\title{
CHARACTERISTICS OF COVID-19'S EPIDEMIC PROCESS IN RUSSIA, MARCH-JUNE 2020
}

\author{
N. Yu Pshenichnaya ${ }^{1}$, I. A. Lizinfeld ${ }^{1}$, G. Yu. Zhuravlev ${ }^{1}$ \\ ${ }^{1}$ Federal Budgetary Institution of Science "Central Research Institute of \\ Epidemiology" of Rospotrebnadzor, Moscow, Russia
}

Background: The epidemic process with local transmission began in Russia in March 2020 [1]. Since the beginning of registration of cases of COVID-19, many states have developed and began to use statistical reporting forms to collect epidemiological and clinical information and create databases on this infection $[2,3]$.

Aim of study: to estimate the dynamics of epidemic process in Russia.

Materials and methods: data analysis of report form \#970 of Federal Service for Surveillance on Consumer Rights Protection and Human Wellbeing about COVID19 cases during the first half of 2020 .

Keywords: epidemic process, age groups, severity, COVID-19, Russia

Results: COVID-19 lockdown was introduced in Russia in the end of March, 2020. But in Moscow and Moscow Region (MaMR) the restrictive measures was input in the first half of March, 2020. Accurately monitoring and isolation of patients and contacts enabled to slow the reaching of peak of illness. Growth rate was 5,0-29,2\% during March-April, 2020 (from 72 to 1800 cases daily). The peak of 7446 new cases was registered in MaMR in May 6, 2020, whereafter the number of cases began to decrease: by $59,4 \%$ by May 31,2020 and 84,9\% by June 29, 2020.

The introduction of similar measures in other regions often were performed with delay and less control. The peak of number of cases was reached since $14^{\text {th }}$ until $17^{\text {th }}$ of May, 2020 with the maximum of 6021 new cases in May 21, 2020. This had 
an impact on long-lasting plateau phase and slow pace of decreasing cases' number. It reduced just by 3,5\% (5808 new cases) by June 1, 2020; by 43,8\% (3381 new cases) by June 28, 2020. Reduction in the daily number of cases in the other regions is progressing slowly compared to MaMR.

Mild cases of COVID-19 were registered in 50,1 $\pm 0,13 \%$. moderate cases in $45,1 \pm 0,13 \%$ and, severe forms in 4,8 $\pm 0,06 \%$. Of all 141907 patients taken into this study the largest number were aged 41-64 years old (44,4 $\pm 0,13 \%)$ and $18-40$ years old $(30,2 \pm 0,12 \%)$. Children of a tender years (0-6 years old) represented $2,7 \pm 0,04 \%$; the group of $7-17$ years was $4,02 \pm 0,05 \%$. Patients aged 65 years and above amounted to $18,66 \pm 0,10 \%$.

Conclusion: Russia has specific characteristics of the epidemic process with significal differences of epidemic curves in the MaMR and other regions due to less strong restrictive measures outside of MaMR.

\section{Conflict of interest:}

The authors declare no possible conflicts of interest.

\section{References:}

1. Kutyrev V.V., Popova A.Yu., Smolensky V.Yu., Ezhlova E.B., Demina Y.V., Safronov V.A., Karnaukhov I.G., Ivanova A.V., Shcherbakova S.A. Epidemiological Features of New Coronavirus Infection (COVID-19). Communication 1: Modes of Implementation of Preventive and Anti-Epidemic Measures. Problems of Particularly Dangerous Infections. 2020;(1):6-13. (In Russ.) https://doi.org/10.21055/0370-1069-2020-1-6-13

2.Wang CJ, Ng CY, Brook RH. Response to COVID-19 in Taiwan: big data analytics, new technology, and proactive testing. Jama. 2020 Apr 14;323(14):1341-2.

3.Raifman J, Nocka K, Jones D, Bo, J, Lipson S, Jay J, et al. COVID-19 US State Policy Database. Ann Arbor, MI: Inter-university Consortium for 
Political and Social Research [distributor], 2020-06-04. https://doi.org/10.3886/E119446V1.

\section{Information about authors:}

Natalia Yu. Pshenichnaya, DSci., Prof; Deputy Director on clinical and analytical work of the Central research Institute of Epidemiology of Rospotrebnadzor, Moscow, Russia; e-mail: nataliapshenichnaya@yandex.ru; ORCID: http://orcid.org/0000-0003-2570-711X;

Irina A. Lizinfeld - MD, Consultant of the organizational and methodological department of the Central Research Institute of Epidemiology of Rospotrebnadzor, Moscow, Russia; e-mail: irinalizinfeld@gmail.com; https://orcid.org/0000-0002-8114-1002

Grigory Yu.Zhuravlev - MD, resident - physician of the Central Research Institute of Epidemiology of Rospotrebnadzor, Moscow, Russia; e-mail: grigory.y.zhuravlev@gmail.com, https://orcid.org/0000-0003-2467-7000 